\title{
DISCUSSION ON THE CONCEPTS OF "COORDINATION" AND "AGILITY" IN TERMS OF PHYSICAL EDUCATION
}

Zaporozhanov V.A., Boraczynski Tomasz

Jozef Rusiecki Olsztyn University College

\begin{abstract}
Annotation. In the scientific and methodological literature and practice of physical education concepts of "coordination" and "agility" are often used synonymously. And discussion about the appropriateness distinguish these concepts is mainly analytical character. Purpose: to evaluate the nature of the relationship metrically between indicators kinesthesia (which characterize the internal processes of interaction in the neuro-muscular system - coordination) and the efficient delivery of a complex exercise (in cooperation man in the external environment of physical education agility). Material: 77 students surveyed. Students performed on 100 strikes the ball into the goal in terms of golf (10 control measurements). The experiment was conducted for 8 months. 7700 measurement precision of centimeters processed statistically. Calculated reliability of measurements: 100 comparability repetitive beats, accuracy hitting the ball into the goal and the pace of learning in terms of the impact of blows. Results: the total volume measurements was characterized by high variability $(\mathrm{V} \%=53,5)$, indicating that the low status of kinesthesia surveyed. This reduces the reliability of the correlation coefficients according to 30 and then 10 of the best students in the general rank in terms of reliability of measurements. Significant correlation occurred only in terms of performance beats the purpose of learning the technique and pace $(0,417 ; \mathrm{n}=30, \mathrm{p}<0,05$; and 0,$677 ; \mathrm{n}=10, \mathrm{p}<0,05)$. Conclusions: Overall, the results of our study showed that the concept of "coordination" and "agility" should still be distinguished. In some cases, students with a good level of kinesthesia occurred and high mobility in complex locomotion. If we recognize it expedient to continue this discussion, then we must rely on objective, metric information. This information should be obtained in studies with a broad contingent surveyed, consistently show good concentration and high reliability results in a series of repeated measurements.
\end{abstract}

Keywords: concepts, coordination, agility, differences, discussion, physiology, physical education.

\section{Introduction}

In special literature on physical education in many cases one can see publications, in which conceptions "coordination" and "dexterity" are used as synonyms [1, 2, 5, 12, 13, 14]. Probably it stimulates still continuing discussion about sense of these conceptions, which had begun in the middle of the past century [6,7]. By the present time these conceptions have been come, to some extent, to opinion that "coordination" reflects mainly internal processes of nervous-muscles formations' interactions in separate muscles and processes of synergetic muscles as well as antagonistic ones in conditions of elementary local motions. While conception "dexterity" characterizes effectiveness of the fulfilled human motion functioning in conditions of external interactions of specific for different life aspects, including kinds of sports; and it is evaluated in wide spectrum of quantitative (metric) and qualitative units [6, 8,10 , $11]$.

It can be assumed that main position for such discussion is idea that initially human physical quality is based on explanation of specific physiological mechanisms, conditions of manifestation, units of measurement and peculiar approaches in process of perfection. Certain difference in conceptions "coordination" and "dexterity" can be connected with certain units of measurements and conditions of registration. For example, for measurement of internal processes in nervous-muscular system electric myography methods and appropriate units of measurement are used, while in conditions of physical education- quite different methods. But in this case we also assume that coordination and dexterity can be evaluated in the same conventional units of measurements, characterizing rate of perfection quantitatively in percents (\%) or qualitatively in terms "high", "middle" or "low". Because, in general, in the base of conceptions "coordination" and "dexterity" there are general physiological mechanisms, which regulate accuracy of differentiation of power, time and space characteristics of both elementary and complex local motions, quickness of their mastering in different conditions, including in physical education. This assumption is grounded in fundamental works of known specialists and is undoubted [1,5]. In our opinion specifying of conceptions "coordination" and "dexterity" can be realized by means of metric evaluation of interconnection between internal processes in nervousmuscular system ("coordination") and processes, which influence on effectiveness of complex, multi-joints human local motions in external conditions ("dexterity").

\section{Purpose, tasks of the work, material and methods}

The purpose of the work is to realize metric evaluation of interconnection between kinesthesia indicators, characterizing internal processes in nervous-muscular system (coordination) and effectiveness of complex exercise, which characterize interactions of a person in external conditions of physical education (dexterity).

All logic of the research was the following: first, we considered that human kinesthesia (muscular sense) reflects the most objectively nervous-muscular processes, have genetic and phenotypic character and can correspond to conception "coordination"; second, in case of our determination of confident correlation between kinesthesia indicators and external effect of behavior of the tested in conditions of physical education (dexterity), these conceptions can be understood as synonyms. Then, with evaluation of every of this conception it could be possible to use common means, 
methods and units of measurement. If there is no substantial, metrically proved interconnections between these conceptions, they shall be understood as different and different conditions and units of measurements shall be used for their evaluation.

The main task for realization of our purpose was determination of level of correlation interconnection between kinesthesia indicators, as ability to reliably reproduce nervous-muscular efforts in series of repeated control exercise and indicators of efficiency and rate of mastering of complex, multi-joint exercise, as ability to adapt to external environmental conditions.

The methods of the research: in our research 77 physical education students of Olshtynskaya higher school participated. All they did not know golf techniques. During eight months we conducted 10 control sessions with 3-4 weeks' intervals. In every control session student fulfilled 10 strikes on ball in target from 9 meters' distance, in conditions of game's imitation. This test was carried out in gym, on synthetic floor covering, on which target of strike (hole) and target, calculated in centimeters in sagittal and frontal planes from hole were marked. It permitted to register accuracy of ball strike in general field of target in permanent climatic and space conditions. In total of 10 control sessions we received 7700 results from 77 tested students. These results were processed with the help of program STATISTICA 71. We calculated correspondence of total mass of measurements to requirements of static distribution of Gauss. Reliability, as comparability of ball strikes' accuracy in scope of 40 consequent measurements of every student, was calculated with in-test correlation method $\left(r_{t t}\right)[3,4,9]$. These data permitted to classify the contingent of the tested in compliance with commonly accepted metrological requirements for evaluation of measurements' reliability by scale "low" - 0.69-0.60; "acceptable" - 0.79-0.70; "middle" - 0.89-0.80; "good" - 0.94-0.90; "excellent" - 0.99-0.95.

Basing on these data we ranged contingent of the tested by indicators of measurements' reliability, which characterized kinesthesia and permitted to indirectly judge about level if internal processes in nervous-muscular system of this contingent.

In the same way we ranged only 30 participants, measurements' reliability of whom met the required metrological requirements also by two other indicators: efficiency of strikes and rates of mastering of strikes' accuracy in the process of testing. For calculation of interconnection between these two indicators we used method of range correlation by Spirman.

Results: As we can see in table 1 total results of strikes' accuracy of every from 77 tested, in conditions, imitating this exercise (in 10 control tests -7700 strikes) were highly various and, as a result, they were low reliable ( in series of 100 consequent strikes - within $53.5 \%$ ).

Table 1.

Mean results of ball strikes' accuracy (in target) I first (1-2) and finalizing (9-10) tests $n=77$ )

\begin{tabular}{|c|c|c|c|c|c|}
\hline Results, cm & & & & \multicolumn{2}{|c|}{ Rate of mastering } \\
\cline { 3 - 6 } & $1-2$ & $9-10$ & $\mathrm{~cm}$ & 27.6 \\
\hline $\mathrm{M}$ & 80.9 & 63.4 & 72.2 & 17.5 & 7.6 \\
\hline$\pm \delta$ & 39.6 & 36.8 & 38.2 & 2.8 & 50.0 \\
\hline $\min$ & 200 & 10.0 & 15 & 10.0 & 5.0 \\
\hline $\max$ & 147 & 140 & 143 & 7.0 & 18.6 \\
\hline $\mathrm{V} \%$ & 48.9 & 58.0 & 53.5 & 9.1 & \\
\hline
\end{tabular}

Mean rates of technique's mastering by indicator of strikes' accuracy were only $27.6 \%$ by the end of testing. It is interesting that high rate of strikes accuracy's increment (up to 50\%) was demonstrated by little part of those participants, who had higher indicator of reliability already in first control tests. Those, who initially were at the end of group's range by this indicator, were the last also by rates of mastering. Rate of increment of these students' results was only $5.0 \%$.

Thus, content of all group of the tested turned out to be quite different by level of muscular sense (kinesthesia), which was initially taken as characterizing internal processes in nervous muscular system (coordination). We did not think it to b correct to carry out further statistic calculations by these data. Such situation forced us to choose from 77 of the tested only that part, members of which had results in first and second series the most comparable and reliable in respect to metrological requirements (see table 2).

Basing on material of this table, in order to solve the tasks of our research, for further statistic operations we chose group from 30 participants, whose measurements' reliability corresponded to good (n-1), middle (n-6) and acceptable (n-23) criteria. It permitted to consider that the following statistic calculations of interconnection between internal mechanisms of nervous-muscular system and effectiveness of complex local motions' formation in conditions of external environment can be objective. Results of this part of the research are given in table 3 , where we can see, to what extent certain internal processes, including kinesthesia (coordination) influenced on formation of motion functioning - efficiency of strikes and quickness of technique's mastering (in our case golf technique) (dexterity). 
Table 2.

Kinesthesia of the tested $(n=77)$ in respect to metrological requirements of measurements' reliability $\left(r_{t t}\right)$ in first $(1-2) u$ and finalizing (9-10) testing

\begin{tabular}{|c|c|c|}
\hline \multirow[t]{2}{*}{ Criteria of reliability $\left(\mathrm{r}_{\mathrm{tt}}\right)$} & \multicolumn{2}{|c|}{ Quantity of the tested } \\
\hline & $1-2$ & $9-10$ \\
\hline High - $\quad 0.95-0.99$ & - & - \\
\hline Good - $0.90-0.94$ & 1 & 1 \\
\hline Middle - $\quad 0.80-0.89$ & 4 & 6 \\
\hline Acceptable - 0.70-0.79 & 26 & 33 \\
\hline Low - $\quad 0.60-0.69$ & 46 & 37 \\
\hline
\end{tabular}

By the control data of 30 participants from 77 (the best in range, kinesthesia of whom corresponded to acceptable criteria of measurements' reliability ( $\mathrm{r}=0.70-0.79)$, we did not find confident correlation with efficiency of ball strikes in target and rate of mastering in series of ten consequent control measurements (in total 100 strikes) $(\mathrm{r}=0.354$ and $0.279 ; \mathrm{p}>0.05)$. In this group there was confident interconnection only between accuracy of strikes in target and rate of technique's mastering by indicator of accuracy in ten series $(r=0.417 ; \mathrm{p}<0.05)$.

Table 3.

Results of correlation analysis of kinesthesia indicators, efficiency of ball strikes in target and quiclnes of technique's mastering in sub groups $\boldsymbol{A} n-30$ and $\boldsymbol{B} n-10$

\begin{tabular}{|l|c|c|c|}
\hline \multicolumn{1}{|c|}{ Indicators } & 1 & 2 & 2 \\
\hline 1 kinesthesia (reliability of measurements) & $\mathrm{X}$ & 0.354 & 0.279 \\
\hline 2 efficiency of strikes in target & 0.588 & $\mathrm{X}$ & $\mathbf{0 , 4 1 7}$ \\
\hline 3 rate of technique's mastering & 0.602 & $\mathbf{0 . 6 7 7}$ & $\mathrm{X}$ \\
\hline
\end{tabular}

Subgroup B

Notes: statistical confidence of correlation coefficient $R_{s}$, for $n-30 p<0.05=0.361$; for $n-10 p<0.05=0.632$

Uncertainty of correlation analysis results forced us to duplicate this method on material of the tested with indicators in the frames of "middle" $0.80-0.89$ and "good" $0.90-0.94$ reliability. Results of analysis of this category in content of ten tested are given in lower left part of correlation matrix (see table 3). As we can see in table 3 interconnection between reliability indicators, which characterize kinesthesia of the tested, efficiency and rate of technique's mastering turned out to be higher. However, in this part of matrix confident correlation was only in indicators of efficiency and rate of mastering range $(r=0.677 ; \mathrm{p}<0.05)$.

\section{Discussion}

Before starting our researches we hoped to obtain confident metric proof of interconnection of kinesthesia of the tested with ability to accurately fulfill complex movements (golf strike) and quickly master technique of this exercise. The basis for such assumption was fundamental knowledge in physiology of organization of human free movements. Basing on this knowledge kinesthesia, in out opinion, could be regarded as a basis, formed in conditions of accumulation of human motion experience in ontogeny, indirectly influencing on formation of complex motions' skills. Generally speaking results of our researches do not permit to prove this idea owing to a number of objective reasons.

First of all, total mass of measurements (7700 ball strikes made by 77 tested) witnessed about extremely low reproducing and comparability of repeated measurements $(\mathrm{V} \%=53.5)$ and, as result, about weak kinesthesia of this contingent. It reflected also in results of correlation analysis, where we did not find confident correlation between kinesthesia and motion abilities even in 30 the best from 77 tested.

Secondly, we should pay attention to the fact that low reliability, reproducing of measurements in conditions of durable testing was connected with complexity of stabilizing of mental state of the tested, oriented on maximal concentration of attention in every from 100 ball strikes in target.

However, calculations of interconnection between tested abilities by best kinesthesia data in ten of the range resulted in higher correlation coefficients. Three first from the tested in this rage (by kinesthesia indicators) turned out in their positions also by indicators of efficiency of strikes in target and quickness of mastering by the end of testing.

Conclusions

In general, results of our research witnessed that conceptions "coordination" and "dexterity" shall be differentiated. However in some cases, when we worked with students, having high kinesthesia, we registered also high indicators of dexterity in complex motions. If continuation of this discussion is purposeful, it would be necessary to 
base on objective metric information, received in researches with wider contingent of the tested, who would demonstrate stable concentration of attention and high reliability of results in repeated measurements.

\section{References:}

1. Bernshtejn N.A. O lovkosti $i$ ee razvitii [About dexterity and its development], Moscow, Physical Culture and Sport, 1991, 276 p. (in Russian)

2. Godik M.A. Sportivnaia metrologiia [Sport metrology], Moscow, Physical Culture and Sport, 1988,192 p. (in Russian)

3. Zaporozhanov V.A., Borachinski T. Empiricheskaia nadezhnost' diagnosticheskikh i prognosticheskikh ocenok fizicheskikh kondicij detej [Empirical reliable diagnostic and prognostic assessment of physical condition of children]. Pedagogika, psihologia ta mediko-biologicni problemi fizicnogo vihovanna i sportu. 2012, no.11, pp. 38-42. (in Russian)

4. Zaporozhanov V.A., Boraczyński T., On the transfer of skills skill in different conditions of motor activity. Pedagogics, psychology, medical-biological problems of physical training and sports, 2013, vol.9, pp. 25-28. doi:10.6084/m9.figshare.749693

5. Zaporozhanov V.A., About reliable indicator of proprioception in agility control. Pedagogics, psychology, medical-biological problems of physical training and sports, 2013, vol.4, pp. 21-25. doi:10.6084/m9.figshare.693023

6. Zaciorskij V.M. Fizicheskie kachestva sportsmena [Physical qualities of athlete], Moscow, Physical Culture and Sport, 1966, 200 p.

7. Kokhanovich K., Kokhanovich A. Somaticheskie priznaki iunykh gimnastov v sisteme special'noj sportivnoj podgotovki [Somatic symptoms of young gymnasts in the special sports training]. Teoriia i praktika fizicheskoj kul'tury, 2014, no.5, pp. 31-34. (in Russian)

8. Lucenko S.Ia. [Theoretical aspects of the definitions of "coordination" and "agility"]. Problemy fizkul'turnogo obrazovaniia [Problems sports education], Kaliningrad, BFU Kant, 2013, pp. 221-23. (in Russian)

9. Urbakh V.Iu. Biometricheskie metody [Biometric methods], Moscow, Science, 1964, 415 p. (in Russian) Boraczynski T., Zaporozhanov V.A. [Structure kinesthesia terms muscle differentiation joint football]. Pedagogika, psihologia ta mediko-biologicni problemi fizicnogo vihovanna i sportu, 2009, no.12, pp. 221-225. (in Russian)

10. Boraczynski T., Zaporozhanov V. [Learning motor coordination as a criterion for assessing the ability of test]. Pedagogika, psihologia ta mediko-biologicni problemi fizicnogo vihovanna i sportu, 2011, no.10, pp. 110-118. (in Russian)

11. Lapszo J., Giovanis V., Prusik Kr., Prusik K. Balance control contributors - The relationships between leg strength and balance control ability in seniors. Acta of Bioengineering and Biomechanics, 2012, no.3, pp. 3-8.

12. Schmidt R.A., Wrisberg C.A. [Human locomotion]. COS, Warsaw, 2009, 420 p. (in Polish)

13. Starosta W. [Motor coordination capacity]. Warsaw, 2003, 564 p. (in Polish) 
Information about the authors:

Zaporozhanov V.A.: http://orcid.org/0000 00018167 7408; nikola-@ ukr.net; Jozef Rusiecki Olsztyn University College; Bydgoska 33, 10-243 Olsztyn, Poland.

Boraczynski Tomasz: http://orcid.org/0000-0002-7851-666X; osw@ osw.olsztyn.pl; Jozef Rusiecki Olsztyn University College; Bydgoska 33, 10-243 Olsztyn, Poland.

Cite this article as: Zaporozhanov V.A., Boraczynski Tomasz. Discussion on the concepts of ,coordination" and ,agility" in terms of physical education. Pedagogics, psychology, medical-biological problems of physical training and sports, 2015, no.3, pp. 15-19. http:// dx.doi.org/10.15561/18189172.2015.0303

The electronic version of this article is the complete one and can be found online at: http://www.sportpedagogy.org.ua/html/arhive-e.html

This is an Open Access article distributed under the terms of the Creative Commons Attribution License, which permits unrestricted use, distribution, and reproduction in any medium, provided the original work is properly cited (http:// creativecommons.org/licenses/by/3.0/deed.en).

Received: 01.02.2015

Accepted: 20.02.2015; Published: 23.02.2015 